\title{
A dignidade humana e os direitos fundamentais da pessoa com deficiência
}

The humane dignity and the fundamental human rights
of person with disabilities

Laryssa Wolff Diniz ${ }^{1}$

Thayliny Zardo ${ }^{2}$

Josemar de Campos Maciel ${ }^{3}$

${ }^{1}$ Mestre em Desenvolvimento Local pela Universidade Católica Dom Bosco, Programa de Pós-graduação em Desenvolvimento Local Mestrado e Doutorado. E-mail: lary_wolff@hotmail.com

${ }^{2}$ Doutoranda e mestre em Desenvolvimento Local pela Universidade Católica Dom Bosco, Programa de Pósgraduação em Desenvolvimento Local - Mestrado e Doutorado. E-mail: thay_zardo@hotmail.com

${ }^{3}$ Doutor em Psicologia pela PUC - Campinas e Professor titular da Universidade Católica Dom Bosco, Programa de PósGraduação em Desenvolvimento Local - Mestrado e Doutorado. E-mail: maciel50334@yahoo.com.br 


\section{RESUMO ABSTRACT}

Pessoas com deficiência têm grandes dificuldades em relação a sua inserção, participação e pertencimento social. Mesmo considerando que houve grandes avanços na legislação e nas práticas, ainda há muito a ser feito. $\mathrm{O}$ trabalho que aqui vai marca um ponto nesse sentido, apresentando e tentando uma síntese do que existe no campo da legislação e em algumas iniciativas de prática, para beneficiar as pessoas que vivem com deficiências. Mas que não precisam ser invisíveis, nem excluídas. Para isso é apresentada uma sucinta revisão de literatura jurídica e uma narrativa de iniciativas de inclusão que vieram aparecendo ao longo da história. Com isso, espera-se contribuir com a discussão acerca da superação dos problemas desses importantes atores territoriais que são as pessoas que convivem com deficiências.

\section{PALAVRAS-CHAVE}

\author{
direitos humanos \\ pessoas com deficiência \\ (in)visibilidade
}

People with disabilities have great difficulties to obtain satisfying levels of inclusion, social participation and belonging. Even though there have been great advances in law and in social practices, there is still much to be done. This essay will mark a small point in that direction, presenting an overview of what exists in the field of legislation and some practical initiatives to benefit people that live with disabilities, but that need not be invisible, or excluded. One presents then a brief legal literature review and a narrative of the history of initiatives of inclusion that can be observed throughout history. With this we hope to contribute to the discussion about overcoming the problems of these important territorial actors, viz., people living with disabilities

\section{KEY WORDS}

human rights people living with disabilities (in) visibility 


\section{CONSIDERAÇõES INICIAIS}

Desde os tempos passados, a discriminação, em suas mais variadas facetas, se faz presente na história brasileira. Opção sexual, etnia, opinião política, religião e deficiência, por exemplo, marcam alguns dos principais pontos de conflito da sociedade e que acabam por prejudicar, por conseguinte, a evolução dos seres humanos. Toda essa discriminação afeta negativamente o desenvolvimento econômico e social e promove o aumento da exclusão social nas comunidades a contrariu sensu do que dispõe a Constituição Federal de 1988, em seu Art. 5o, garantindo a igualdade de todos perante a lei.

A inclusão dos portadores de deficiência no Brasil envolve aproximadamente 45,6 milhões de pessoas, representando, portanto, em torno de $24 \%$ da população, que se dizem possuir pelo menos um tipo de deficiência (IBGE, 2010). Nessa linha, ainda que o percentual de pessoas com deficiência represente quase $1 / 4 \mathrm{da}$ população brasileira, muito ainda há de ser feito, seja no campo da educação, do mercado de trabalho e, até mesmo, no tratamento sem discriminação. 0 quadro de marginalização dessas pessoas necessita ser mudado e, para isso, passos fundamentais devem ser dados, principalmente no que se refere à garantia dos direitos fundamentais.

Desse modo, o objetivo deste texto é buscar evidenciar, ainda que brevemente, a importância da inclusão social dos portadores de deficiência, seja para a política, economia, seja para a cultura social, de forma que a acessibilidade a todos os setores da sociedade seja vista como uma política pública urgente e imediata a ser posta em prática. 


\section{BREVE APONTAMENTO HISTÓRICO DOS DIREITOS HUMANOS E FUNDAMENTAIS}

Toda e qualquer pessoa, ao nascer, já tem garantida sua dignidade, a qual deverá ser respeitada, independentemente de quaisquer diferenças, seja no agir, no movimentar-se, no pensar, entre outros. Todavia tanto a dignidade humana quanto os direitos fundamentais nem sempre tiveram a importância que têm hoje e, para se chegar nessa fase de exigência do respeito ao próximo, uma parte cruel na história da humanidade precisou ser vivida.

Antes da Segunda Guerra Mundial, estava em ascensão o positivismo, que tinha como linha de pensamento a obediência incondicional, pelas autoridades públicas e cidadãos, das normas estabelecidas pelo líder do Estado, independentemente do conteúdo que possuíssem. Adolf Hitler, por exemplo, seguia o positivismo e usava isso como arma contra os judeus, conforme aponta Marmelsteins (2011, p. 04):

Hitler tinha perfeita noção de significado dos direitos do homem ao dizer que eles estão acima dos direitos do Estado. Não obstante isso, sua concepção é completamente distorcida e discriminatória, já que somente os descendentes de uma suposta "raça superior" deveriam ter o privilegio de gozar esses direitos. Os demais seres humanos poderiam ser descartados; afinal, "o mundo não foi feito para os povos covardes". Para Hitler, a dignidade não era atributo do ser humano como um todo, mas dos seletos membros da raça ariana.

Como consequência desse pensamento aconteceu o que ficou chamado de Holocausto, marcado pela morte de milhões de judeus e de outras minorias, por meio de atos de crueldade como torturas, experimentos médicos com seres humanos, esterilização, pena de morte e muitas outras atrocidades, todas protegidas pelo regime legal vigente da época na Alemanha.

Com o fim da Segunda Guerra Mundial, um importante passo para a humanidade foi dado, pois houve a queda do nazismo e, 
consequentemente, deu-se ênfase à dignidade humana, devido à instauração do julgamento de Nuremberg - um tribunal feito para julgar os crimes praticados pelos nazistas contra a humanidade, estabelecido pelos países vencedores da guerra.

Sendo assim, devido a sua importância, Nuremberg representou um marco importante para toda a ordem mundial, reconhecendo-se a dignidade humana como um valor acima da própria lei e do Estado.

Nessa linha, explica bem Marmelsteins (2011, p. 09):

A partir do Julgamento de Nuremberg, qualquer violação à dignidade humana praticada como política de governo passou a constituir desrespeito à humanidade como um todo. "Os direitos do homem estão acima dos direitos do Estado"- eis, em síntese, o significado do julgamento de Nuremberg.

Com o fim desse período, o positivismo foi descartado e iniciou-se a fase do pós-positivismo, buscando a proteção da dignidade humana. Essa nova fase trouxe o respeito aos valores e princípios como os pontos principais na criação de normas, sendo, portanto, o alicerce para a Constituição.

Por sua vez, a Constituição Federal de 1988 é a base que mostra o rumo a ser seguido pela sociedade, elencando os princípios fundamentais da dignidade humana, igualdade, solidariedade, entre outros, cuja observância é obrigatória por parte da coletividade.

Essa nova forma de ver o mundo fez com que surgissem novas questões a serem discutidas, a exemplo do direito do deficiente em viver de forma igualitária na sociedade.

Por esse motivo, as pessoas com deficiência são iguais a todos os outros agentes sociais, razão pela qual merecem o respeito e consideração do Estado e da sociedade, conforme dispõe Sarlet (2002, p. 62):

Qualidade intrínseca e distintiva reconhecida em cada ser humano que o faz merecedor do mesmo respeito e consideração por 
parte do Estado e da comunidade, implicando, neste sentido, um complexo de direitos e deveres fundamentais que assegurem a pessoa tanto contra todo e qualquer ato de cunho degradante e desumano, como venham a lhe garantir as condições existências mínimas para uma vida saudável, além de propiciar e promover uma participação ativa e corresponsável nos destinos da própria existência e da vida em comunhão com os demais seres humanos, mediante o devido respeito aos demais seres que integram a rede da vida.

Denota-se então que está a se falar da autovalorização da pessoa, em que o respeito entre os seres sociais deve ser mútuo, ou seja, de uns para com os outros, de modo que os direitos fundamentais, assegurados pela Constituição Federal de 1988, e que visam à proteção da pessoa humana, não sejam violados.

Os direitos fundamentais constituem o direito de locomoção, ao trabalho, à saúde e à educação inclusiva, por exemplo, dentre outras prerrogativas necessárias ao direito à cidadania.

Dessa forma, cabe ao Estado o dever de tutelar a dignidade humana, seja por meio de ações concretas e medidas positivas, tais como a adaptação de calçadas para deficientes visuais, como formas de garantir o respeito e assegurar a dignidade das pessoas com deficiência.

Atualmente, a luta dos portadores de deficiência por uma sociedade mais digna e acessível tornou-se um tanto quanto mais visível, apesar de ainda carecer de maiores atenções. Essa batalha por direitos que assegurem a dignidade dos portadores de deficiência iniciou-se por volta dos anos 70 e 80, quando ocorreram as primeiras movimentações, merecendo destaque a Declaração Universal dos Direitos do Deficiente na proclamação da Assembleia Geral da ONU, em 9 de dezembro de 1975, que assim assegurava:

3- As pessoas deficientes têm o direito inerente de respeito por sua dignidade humana. As pessoas deficientes, qualquer que seja a origem, natureza e gravidade de suas deficiências têm os mesmos direitos fundamentais de seus concidadãos da mesma 
idade, o que implica, antes de tudo, o direito de desfrutar de uma vida decente, tão normal e plena quanto possível. (ONU, s.d, s.p.).

A partir de então, novos movimentos políticos dos portadores de deficiência passaram a fazer parte do universo social, com vistas à garantia de sua cidadania e dos direitos humanos. Exemplo disso foi a Convenção sobre os Direitos das Pessoas com Deficiência, ratificada no Brasil em 2008, sendo o primeiro tratado de Direitos Humanos internalizado no sistema jurídico brasileiro, o qual ganhou o status formal de norma constitucional, nos termos do Art. $5^{\circ}, \S 3^{\circ}$ da Constituição Federal de 1988, ora denominada $\mathrm{CF} / 88$, com o seguinte protocolo facultativo:

Promover, proteger e assegurar o desfrute pleno e equitativo de todos os direitos humanos e liberdades fundamentais por parte de todas as pessoas com deficiência e promover o respeito pela sua dignidade inerente.

Portanto resta evidente a relação do princípio da dignidade humana com os direitos fundamentais, assim como resta claro que, na maioria das vezes, referidos direitos não são respeitados quando se trata das pessoas com deficiência, sendo necessárias medidas para assegurar uma vida normal e com todos os direitos que lhes pertencem.

Dessa forma, é fácil perceber o poder dos direitos fundamentais para se ter uma vida digna, tendo seus direitos respeitados e vivendo em harmonia com toda sociedade, deixando de lado todos os preconceitos e tratando o próximo com igualdade.

\section{DOS DIREITOS FUNDAMENTAIS DA PESSOA COM DEFICIÊNCIA}

Cumpre observar, ainda que brevemente, alguns direitos fundamentais inerentes à pessoa com deficiência, desde suas teorias até a efetivação de sua garantia no ordenamento legal, conforme delineado a seguir. 


\subsection{Direito à igualdade}

A teoria e a prática do princípio da igualdade e dos direitos de igualdade possuem grande relevância quando o assunto são pessoas com deficiência, pois trata-se de pessoas particularmente vulneráveis às práticas discriminatórias, sejam elas diretas ou indiretas.

0 princípio da igualdade possui como principal função eliminar o preconceito e acabar com a diferenciação e discriminação feitas pela sociedade. A igualdade obteve lugar de acentuado destaque em várias passagens do texto constitucional, a começar pelo Preâmbulo.

Por meio dele, a igualdade e o valor de uma sociedade pluralista e sem preconceitos integram os valores centrais da ordem jurídico-constitucional. Tal princípio possui definição no artigo 50, caput, da Constituição Federal vigente, que assim dispõe:

Art. 5ํ. Todos são iguais perante a lei, sem distinção de qualquer natureza, garantindo- se aos brasileiros e aos estrangeiros residentes no País a inviolabilidade do direito à vida, à liberdade, à igualdade, à segurança e à propriedade.

No entanto, a $\mathrm{CF} / 88$ não se limitou a enunciar um direito geral de igualdade, mas estabeleceu, ao longo do texto, uma série de disposições impositivas de um tratamento igualitário e proibitivas de discriminação, caso da igualdade entre homens e mulheres (art. $5 \stackrel{\circ}{\circ}$ I), de exercício de funções e de critério de admissão por motivo de sexo, idade, cor ou estado civil (art. 7ํㅡ, $\mathrm{XXX}$ ), entre outros.

Dessa forma, igualdade passou a constituir valor central para o direito constitucional contemporâneo, faz parte da tradição constitucional que teve seu início com as primeiras declarações de direitos e sua incorporação aos catálogos constitucionais desde o constitucionalismo de matriz liberal-burguesa. Pode-se observar, nas palavras de Canotilho e Moreira (2007, p. 336-337), que: 
O princípio da igualdade é um dos princípios estruturantes do sistema constitucional global, conjugando dialeticamente as dimensões liberais, democráticas e sociais inerentes ao conceito de Estado de direito democrático e social.

A igualdade de todos perante a Lei traz o princípio da isonomia, que consiste em tratar igualmente os iguais e desigualmente os desiguais, porém, tais deveres, implicam um ônus argumentativo no sentido de uma justificação, de eventual tratamento desigual, pois o que é vedado é toda e qualquer desigualdade de caráter arbitrário. Portanto, não justificável, já que o princípio da igualdade não exige que o legislador deva tratar todos da mesma maneira, ou que todos devam ser iguais em todos os aspectos. Nesse sentido, Paulo e Alexandrino (2011, p. 121-122) afirmam que:

A igualdade na lei tem por destinatário precípuo o legislador, a quem é vedado valer-se de lei para estabelecer tratamento discriminatório entre pessoas que mereçam idêntico tratamento, enquanto a igualdade perante a lei dirige-se principalmente aos intérpretes e aplicadores da Lei, impedindo que, ao concretizar um comando jurídico, eles dispensem tratamento distinto a quem a lei considerou igual.

Sendo assim, a igualdade equivale à noção de que todos os homens são iguais, compreendida no sentido de uma igualdade absoluta em termos jurídicos. Corresponde ao direito de toda e qualquer pessoa de estar sujeita ao mesmo tratamento previsto na lei, independentemente do conteúdo do tratamento dispensado e das condições e circunstâncias pessoais.

\subsection{DIREITO AO TRABALHO E AO EMPREGO}

Possuir um trabalho não está relacionado apenas ao fato de ter um emprego, mas também de poder exercer uma atividade, promover o próprio sustento, sentir-se útil, ser digno de respeito por aquilo que faz. Esse é o sentimento da maioria das pessoas e não é diferente para quem possui algum tipo de deficiência. 
Assim, não deve existir exclusão dessas pessoas quando o assunto é trabalho, de forma que cabe aos estados constituírem mecanismos que assegurem a proteção e as garantias laborais às pessoas com deficiência.

Faz-se necessária a proibição de práticas e promoção de direitos decorrentes. Afinal, o trabalho é um direito inalienável da pessoa, incluindo as pessoas com deficiência.

Na CF/88 em seu artigo 7º, inciso XXXI, há a proibição da discriminação em relação ao trabalhador portador de deficiência dispondo que:

Art. 7ํ. São direitos dos trabalhadores urbanos e rurais, além de outros que visem à melhoria de sua condição social:

XXXI - proibição de qualquer discriminação no tocante a salário e critérios de admissão do trabalhador portador de deficiência.

Configura-se violação direta à igualdade e aos valores inerentes à pessoa, caso seja comprovada, a discriminação baseada na deficiência. Mas, infelizmente, mesmo sendo uma violação, tal discriminação ainda existe e normalmente ocorre por ação ou omissão, de forma direta ou indireta.

As duas formas acima citadas de discriminação estão mais bem explicadas por Gugel (2006, p. 56):

Formas direta e indireta de discriminação: direta, quando contém determinações e disposições gerais que estabelecem distinções fundamentadas em critérios proibidos e já definidos em lei, sendo de fácil caracterização quando, por exemplo, proíbe-se a entrada de uma pessoa em um clube por ser negra; indireta está relacionada com situações, regulamentações ou práticas aparentemente neutras, mas que, na realidade, criam desigualdades em relação a pessoas que têm as mesmas características. Ela poderá ser imperceptível mesmo para quem está sendo discriminado, como nos casos de processos de seleção para empregos baseada não só no histórico profissional e de qualificação do candidato, mas no seu desempenho em entrevista. É nesse momento que se revela o entrevistador preconceituoso ou que detém ideias preconcebidas, que tem predisposição a respeito de alguém ou de algum grupo. 
Sobre este assunto, a Lei n. 7.853/89 (art. $8^{\circ}$, II) informa que negar, sem justa causa, emprego ou trabalho a alguém por motivos derivados de sua deficiência é conduta típica de crime. Do mesmo modo, é crime quando da admissão do trabalhador com deficiência, bem como, no curso de seu contrato de trabalho, o empregador lhe negar uma promoção ou rescindir o contrato de trabalho em razão da deficiência portada.

Além da igualdade de tratamento, é necessário que haja a integração do deficiente à sociedade, e um grande passo para que isso ocorra se dá com a entrada do deficiente no mercado de trabalho, fazendo com que seja mais fácil a integração com todos.

No Art. 5 da Convenção sobre os Direitos das Pessoas com Deficiência da ONU, fica claro o dever de igualdade e não discriminação:

Igualdade e não discriminação 1. Os Estados Partes reconhecem que todas as pessoas são iguais perante e sob a lei e que fazem jus, sem qualquer discriminação, à igual proteção e igual benefício da lei. 2. Os Estados Partes deverão proibir qualquer discriminação por motivo de deficiência e garantir às pessoas com deficiência igual e efetiva proteção legal contra a discriminação por qualquer motivo. 3. A fim de promover a igualdade e eliminar a discriminação, os Estados Partes deverão adotar todos os passos necessários para assegurar que a adaptação razoável seja provida. 4. Nos termos da presente Convenção, as medidas específicas que forem necessárias para acelerar ou alcançar a efetiva igualdade das pessoas com deficiência não deverão ser consideradas discriminatórias.

A partir do momento em que a pessoa com deficiência ingressa no mercado de trabalho, é necessário que aconteçam algumas adequações no ambiente de trabalho. São exigidas algumas modificações, ajustes necessários e adequados para cada caso, no entanto que não acarretem ônus desproporcional ou indevido. De forma geral, essas alterações devem assegurar às pessoas com deficiência que possam gozar ou exercer em igualdade de oportunidades com as demais pessoas todos os direitos humanos e liberdades fundamentais. 
Como forma de auxiliar as adequações permanentes necessárias na sociedade, foi criado o desenho universal, que visa à concepção de produtos, ambientes, programas e serviços a serem usados, na maior medida possível, por todas as pessoas, sem necessidade de adaptação ou projeto específico.

É o ideal a ser desfrutado por toda sociedade, composta de pessoas diferentes umas das outras e que fazem parte da diversidade humana. 0 desenho universal, no entanto, não inibirá o direito da pessoa com deficiência às ajudas técnicas específicas, por ser um direito inalienável das pessoas com deficiência.

Além das mudanças necessárias nas estruturas físicas, é preciso estar atento à proteção de direitos, devendo os órgãos de justiça (tribunais e juízes) e as instituições essenciais à justiça (Ministério Público, Defensoria Pública e Advocacia) estarem solidariamente preparados e organizados para assegurar o acesso de pessoas com deficiência, tendo em vista que a sociedade é um estado democrático de direito, fundado nos princípios da cidadania, dignidade da pessoa humana e valores sociais do trabalho.

As condutas de assédio moral, a possibilidade de rescisão do contrato de trabalho e respectiva indenização estão asseguradas quando existe a exigência de serviços superiores às forças do trabalhador ou proibidos em lei, contrários aos bons costumes ou alheios ao contrato. A exemplo disso, quando o trabalhador for tratado pelo empregador ou por seus superiores hierárquicos com rigor excessivo; quando o empregador praticar ato lesivo à honra e boa fama, ofensa física ou reduzir o trabalho de forma a afetar sensivelmente a remuneração do trabalhador. Nesses casos, existe jurisprudência firmada e previsão específica no Art. 483 da CLT.

No que se refere ao concurso público para pessoa com deficiência, a CF/88 no artigo 37, VIII, dispõe que: "a lei reservará percentual dos cargos e empregos públicos para as pessoas portadoras de deficiência e definirá os critérios de sua admissão." Nesse sentido, o Decreto n. 3298/99, editado para regulamentar 
a Lei n. 7.853/89, estabelece como regra geral, que os concursos públicos federal, estadual e municipal deverão prever a reserva de, no mínimo, $5 \%$ das vagas ofertadas no certame, para pessoas com deficiência.

Assim, estabelece a Lei n. 8.213/91, em seu art. 93, que empresas com cem ou mais empregados estão obrigadas a preencher seus cargos com $2 \%$ a 5\% com pessoas com deficiência e beneficiários reabilitados.

\subsection{Direito à educação}

A CF/88 trouxe grandes avanços no que tange ao direito à educação. Konzen (1999, p. 1) analisa o direito à educação na referida Constituição da seguinte forma:

Afirmado como o primeiro e o mais importante de todos os direitos sociais, fez-se compreender a Educação como valor de cidadania e de dignidade da pessoa humana, itens essenciais ao Estado Democrático de Direito e condição para a realização dos ideais da República, de construir uma sociedade livre, justa e solidária, nacionalmente desenvolvida, com a erradicação da pobreza, da marginalização e das desigualdades sociais e regionais e livre de quaisquer formas de discriminação (artigo 3o da Constituição Federal), o imaginário de Nação inscrito na Carta Magna Brasileira.

É por meio da educação que se criam condições de entender os outros direitos e de lutar por sua efetivação, fazendo com que a educação se torne um direito fundamental. Por esse motivo, faz-se necessária a escola para todos, visando a pleno desenvolvimento humano, preparando para o exercício da cidadania e para o trabalho.

Cumpre observar, entretanto, que a educação no Brasil ainda necessita de grandes modificações para tornar uma sociedade livre, justa e solidária, não apenas para as pessoas com deficiência, mas para todos os cidadãos que aprenderiam a conviver com as diferenças, de modo que o papel do educador seja o de despertar 
no aluno a vontade de aprender e de conhecer um mundo novo, incentivando as atitudes de respeito, tolerância e solidariedade. Sobre as escolas dispõe Mantoan (2003, p. 18):

A Escola brasileira é marcada pelo fracasso e pela evasão de uma parte significativa de seus alunos, marginalizados pelo insucesso, por privações constantes e pela baixa autoestima resultante das exclusões escolar e social.

A inclusão total e irrestrita é uma oportunidade que temos para reverter a situação da maioria de nossas escolas, as quais atribuem aos alunos as deficiências que são do próprio ensino ministrado por elas - sempre se avalia o que aluno aprendeu, o que ele não sabe, mas raramente se analisa "o que" e "como" a escola ensina, de modo que os alunos não sejam penalizados pela repetência, evasão, discriminação, exclusão, enfim. (MANTOAN, 2003, p. 28).

Está-se acostumado a relacionar pessoas com deficiência em escolas especializadas nos cuidados com deficientes, porém, essa não é a melhor forma de tratar esse assunto, tanto para o deficiente como para toda a sociedade.

Para resolver este impasse, faz-se necessária a escola inclusiva, que é uma escola para todos, que, além de passar o conhecimento técnico-científico, ensina valores, princípios e atitudes, mostrando como conviver em harmonia com as diferenças.

É comum no dia a dia quem não possui deficiência se deparar com a situação de encontrar uma pessoa que possui e não saber como lidar, de que formar tratar nem mesmo como se sentir diante dessa diferença.

Situações assim dificilmente aconteceriam se essas pessoas fossem introduzidas na sociedade por meio da educação, fazendo com que todos convivam juntos desde os primeiros anos de vida. A respeito disso Araujo (2011, p. 46-47), entende:

Nós (pessoas não portadoras de deficiência) também temos o direito de poder conviver com gente diferente, com problemas diferentes, para aprendermos a ser mais tolerantes; saber como 
nos comportar diante das diferenças; saber que elas são superáveis a partir de uma vivência efetiva e conjunta. Com um ensino segregado, tal direito nos foi (a nós, a maioria) retirado e fomos impedidos de conviver com colegas de classe cegos, surdos, com deficiência mental leve, etc. E a falta desse convívio hoje se revela quando encontramos alguém em cadeira de rodas, por exemplo, e não sabemos muito bem como comportar, o que podemos fazer para ajudar, se é que eles precisam de ajuda. É a falta dessa educação inclusiva que nos faz achar sempre que a pessoa portadora de deficiência precisa de ajuda.

Mas, para que isso aconteça, é necessário que haja adaptação das escolas, pois, inclusão escolar não é apenas colocar alunos com deficiência em sala de aula comum, mas também lhes proporcionar todos os meios necessários para o desenvolvimento.

Afinal o dever da escola é proporcionar o convívio entre os seres humanos, com suas diferenças, fazendo com que a escola que não possua essa possibilidade não seja nem considerada uma escola por ter perdido suas características básicas e essenciais.

Dessa forma, prevê o dispositivo legal da Lei n. 7.853/99, no art. $8^{\circ}$, que é crime recusar, suspender, procrastinar, cancelar ou fazer cessar, sem justa causa, a matrícula de aluno em estabelecimento de ensino de qualquer curso ou grau, público ou privado, por motivos derivados de sua deficiência.

A respeito da educação, dispõe a Convenção Internacional sobre os Direitos das Pessoas com Deficiência em seu Art. 24:

1. Os Estados Partes reconhecem o direito das pessoas com deficiência à educação. Para realizar este direito sem discriminação e com base na igualdade de oportunidades, os Estados Partes deverão assegurar um sistema educacional inclusivo em todos os níveis, bem como o aprendizado ao longo de toda a vida, com os seguintes objetivos: a. O pleno desenvolvimento do potencial humano e do senso de dignidade e auto-estima, além do fortalecimento do respeito pelos direitos humanos, pelas liberdades fundamentais e pela diversidade humana; b. 0 desenvolvimento máximo possível personalidade e dos talentos e criatividade das pessoas com deficiência, assim de suas habilidades físicas 
e intelectuais; c. A participação efetiva das pessoas com deficiência em uma sociedade livre. 2. Para a realização deste direito, os Estados Partes deverão assegurar que: a. As pessoas com deficiência não sejam excluídas do sistema educacional geral sob alegação de deficiência e que as crianças com deficiência não sejam excluídas do ensino fundamental gratuito e compulsório, sob a alegação de deficiência; b. As pessoas com deficiência possam ter acesso ao ensino fundamental inclusivo, de qualidade e gratuito, em igualdade de condições com as demais pessoas na comunidade em que vivem; c. Adaptações razoáveis de acordo com as necessidades individuais sejam providenciadas; d. As pessoas com deficiência recebam o apoio necessário, no âmbito do sistema educacional geral, com vistas a facilitar sua efetiva educação; e e. Efetivas medidas individualizadas de apoio sejam adotadas em ambientes que maximizem o desenvolvimento acadêmico e social, compatível com a meta de inclusão plena.

Portanto é dever do Estado proporcionar medidas de inclusão, facilitando o acesso às escolas, adaptações razoáveis devem ser feitas, e todo apoio necessário tem que ser garantido a essas pessoas, de maneira a existir o pleno desenvolvimento das pessoas desse grupo. 0 Art. 24 da Convenção da ONU também elenca que:

3. Os Estados Partes deverão assegurar às pessoas com deficiência a possibilidade de aprender as habilidades necessárias à vida e ao desenvolvimento social, a fim de facilitar-lhes a plena e igual participação na educação e como membros da comunidade. Para tanto, os Estados Partes deverão tomar medidas apropriadas, incluindo: a. Facilitação do aprendizado do braile, escrita alternativa, modos, meios e formatos de comunicação aumentativa e alternativa, e habilidades de orientação e mobilidade, além de facilitação do apoio e aconselhamento de pares; b. Facilitação do aprendizado da língua de sinais e promoção da identidade linguística da comunidade surda; e c. Garantia de que a educação de pessoas, inclusive crianças cegas, surdocegas e surdas, seja ministrada nas línguas e nos modos e meios de comunicação mais adequados às pessoas e em ambientes que favoreçam ao máximo seu desenvolvimento acadêmico e social. 4. A fim de contribuir para a realização deste direito, os Estados Partes deverão tomar medidas apropriadas para empregar professores, inclusive professores com deficiência, habilitados para o ensino da língua de sinais e/ou do braile, e para 
capacitar profissionais e equipes atuantes em todos os níveis de ensino. Esta capacitação deverá incorporar a conscientização da deficiência e a utilização de apropriados modos, meios e formatos de comunicação aumentativa e alternativa, e técnicas e materiais pedagógicos, como apoios para pessoas com deficiência. 5. Os Estados Partes deverão assegurar que as pessoas com deficiência possam ter acesso à educação comum nas modalidades de: ensino superior, treinamento profissional, educação de jovens e adultos e aprendizado continuado, sem discriminação e em igualdade de condições com as demais pessoas. Para tanto, os Estados Partes deverão assegurar a provisão de adaptações razoáveis para pessoas com deficiência.

Assim, fica claro o que a CF/88 e a Convenção sobre os Direitos das Pessoas com Deficiência da ONU estabelecem em relação ao direito à educação inclusiva, sobre a impossibilidade de, nos dias de hoje, haver ensino em ambiente segregado.

Como diz Claudia Werneck (2000, p. 64):

Incluir não é favor, mas troca. Quem sai ganhando com essa troca? Todos, em igual medida. Conviver com as diferenças humanas é direito do pequeno cidadão, deficiente ou não. Juntos construirão um país diferente. A escola transformadora é a semente desse Brasil-do-tamanho-exato-de-nossas-ideias.

Dessa forma, pode-se observar a necessidade não apenas profissional, mas também como auxílio ao desenvolvimento do ser humano, de se integrar as pessoas com deficiência na educação do nosso país.

\subsection{Direito à saúde}

Como lei maior do ponto de vista hierárquico, a $\mathrm{CF} / 88$, em seu Art. 196, estabelece que:

Art. 196 - A saúde é direito de todos e dever do Estado, garantido mediante políticas sociais e econômicas que visem à redução do risco de doença e de outros agravos e ao acesso universal e igualitário às ações e serviços para sua promoção, proteção e recuperação. 
Dessa forma, fica claro que todos, inclusive as pessoas com deficiência, têm o direito à saúde, consagrado pela Constituição Federal, sendo que o sistema de saúde predominante no Brasil é o público. Portanto a responsabilidade de garantir o atendimento de seus cidadãos, assegurando-lhes o bem-estar, de forma universal, igualitária e gratuita, com possibilidade de complementação pelo setor privado, é do Estado.

A concretização do sistema de saúde brasileiro ocorre por meio do Sistema Único de Saúde (SUS) (Lei Orgânica n. 8.142/90), previsto e delineado também pela Constituição Federal, sendo pontos de destaque a universalidade, que visa beneficiar toda a população brasileira, e a igualdade.

A organização e os parâmetros para a atuação do SUS estão dispostos na Lei n. 8.080/90, conhecida como Lei Orgânica da Saúde, que determina em seu Art. $7^{\circ}$ :

Art. $7^{\circ}$ As ações e serviços públicos de saúde e os serviços privados contratados ou conveniados que integram o Sistema Único de Saúde - SUS são desenvolvidos de acordo com as diretrizes previstas no artigo 198 da Constituição Federal, obedecendo ainda aos seguintes princípios: I - universalidade de acesso aos serviços de saúde em todos os níveis de assistência; II - integralidade de assistência, entendida como um conjunto articulado e contínuo das ações e serviços preventivos e curativos, individuais e coletivos, exigidos para cada casa em todos os níveis de complexidade do sistema; III- preservação da autonomia das pessoas na defesa de sua integridade física e mental; IV - igualdade da assistência à saúde, sem preconceitos ou privilégios de qualquer espécie; VIII- participação da comunidade, IX - descentralização político-administrativa, com direção única em cada esfera de governo: a) ênfase na descentralização dos serviços para os municípios; b) regionalização e hierarquização da rede de serviços de saúde; X - integração em nível executivo das ações de saúde, meio ambiente e saneamento básico; XI - conjugação dos recursos financeiros, tecnológicos, materiais e humanos da União, dos Estados, do Distrito Federal e dos Municípios na prestação de serviços de assistência à saúde da população; XII - capacidade de resolução dos serviços em todos os níveis de assistência; e XIII - 
organização dos serviços públicos de modo a evitar duplicidade de meios para fins idênticos.

Sobre a saúde dispõe a Constituição da Organização Mundial da Saúde (s.d., s.p.) que a saúde é "um estado de completo bem-estar físico, mental e social, e não consiste apenas na ausência de doença ou de enfermidade". Também, deixa claro que:

Gozar do melhor estado de saúde que é possível atingir constitui um dos direitos fundamentais de todo o ser humano, sem distinção de raça, de religião, de credo político, de condição econômica ou social. (OMS, s.d., s.p.).

A pessoa com deficiência possui desvantagens sociais devido à sua dificuldade de se adequar ao meio social. Muitas vezes, para superar essas desvantagens, é necessária uma reabilitação e, em alguns casos, para evitar que aconteça a reabilitação, é feita a prevenção. Assim, é dever do Estado para com a saúde englobar itens como vacinas, internações, exames de apoio ao diagnóstico, medicamentos e, até mesmo, próteses, inclusive externas.

Dessa forma, fica claro que a qualquer pessoa deficiente deve o Estado prestar o atendimento respectivo necessário, conforme as possibilidades existentes, do ponto de vista científico. Porém não basta apenas oferecer tratamentos, é necessário fazer com que haja a inclusão social da pessoa com deficiência.

Com o intuito de promover, por meio da integração e articulação de políticas, programas e ações, o exercício pleno dos direitos das pessoas com deficiência foi instituído pelo Decreto n. 7.612, de 17 de novembro de 2011.

Surgiu, através da Convenção sobre os Direitos das Pessoas com Deficiência, o Plano Nacional dos Direitos da Pessoa com Deficiência, popularmente conhecido como "Plano Viver sem Limite". Esse Plano estabeleceu como metas para a área de saúde, no período 2011-2014, as seguintes ações:

Triagem Neonatal; Teste do Pezinho completo; Sistema nacional de monitoramento e busca ativa; Protocolos Clínicos e Diretrizes 
Terapêuticas; Triagem auditiva neonatal; Deficiências visuais; Síndrome de Down; Autismo; Paralisia cerebral; Amputados; Outras. Rede de Habilitação e Reabilitação; Qualificação dos serviços em parceria com instituições de excelência; 45 Centros de Referência em Habilitação e Reabilitação, com veículos acessíveis; Órteses e próteses; 19 novas oficinas ortopédicas e qualificação de 60 oficinas ortopédicas; Formação de 660 profissionais; Aquisição, adaptação e manutenção de órteses e próteses, inclusive de cadeira de rodas; Atendimento Odontológico. Qualificação de: 420 centros de especialização odontológica; 27 centros cirúrgicos; Capacitação de 6 mil equipes.

Posto isto, cumpre esperar que esses compromissos ainda sejam honrados, fazendo com que exista uma melhoria na saúde pública, beneficiando assim toda a sociedade, em especial as pessoas com deficiência.

\subsection{Direitos da pessoa com deficiência nas relações familiares}

O ser humano necessita da convivência com outras pessoas, todo homem ou mulher, para viver bem, precisa de afeto, atenção e carinho. Para a maioria das pessoas, essa atenção essencial é encontrada no seio familiar, pois é por meio da família que há o primeiro contato com o mundo.

É a partir desse momento que se é apresentado a várias informações, como quem ser e o que esperar a ser, sendo de fundamental importância para o desenvolvimento da pessoa este primeiro contato, como dispõe Buscaglia (1997, p. 78):

[...] desempenha importante papel na determinação do comportamento humano, na formação da personalidade, no curso da moral, na evolução mental e social, no estabelecimento da cultura e das instituições. Como influente força social, não pode ser ignorada por qualquer pessoa envolvida no estudo do crescimento, desenvolvimento, da personalidade ou do comportamento humanos.

Apesar da ciência de que existe a possibilidade de se ter na família alguém que nasça com a deficiência, ou que adquira 
algum tipo de deficiência ao longo da vida, as pessoas não estão preparadas para essa situação.

Ter alguém com limitações na família e não saber como lidar ao deparar com o deficiente é comum, por falta de informação e por não saber como agir, exerce-se um tratamento preconceituoso com essas pessoas. A respeito desse assunto Ribas (1985, p. 22-23) afirma que:

Grande parte das famílias não está preparada para receber um membro deficiente. Acredito mais: que não estão preparadas, principalmente porque receberam toda carga ideológica que reina no interior de nossa cultura. Deste modo, as reações podem ser as mais variadas: rejeição, simulação, segregação, super-proteção, paternalismo exacerbado, ou mesmo piedade.

Importante observar que o agrupamento familiar é indispensável para a própria condição de ser humano. É na família que se encontra a proteção necessária para as relações mantidas com outras pessoas, a exemplo de hipótese de abuso, coação, segregação ou negligência e desrespeito à pessoa com deficiência, seja por empregadores, fornecedores de bens ou serviços ou até mesmo em face de outros membros da família.

Além desse tipo de segurança, é primordial a proteção dos direitos fundamentais, como o direito à moradia, à honra, à vida privada, entre outros, como base fundamental para o desenvolvimento de qualquer pessoa.

0 papel fundamental da família é oferecer o apoio essencial para o desenvolvimento do ser humano, criando ali os alicerces necessários para o futuro de uma pessoa, sendo assim, a ponte entre o berço familiar e a sociedade como se encontra.

Fundada numa ordem constitucional-civil, a família brasileira da atualidade se baseia pelos princípios da dignidade da pessoa humana, da igualdade e do respeito às diferenças, do melhor interesse da criança e do adolescente, da autonomia e da menor intervenção do Estado, da pluralidade e do afeto. 
Sendo assim, a família brasileira contemporânea na sua maior parte busca a felicidade, atém-se ao afeto nas suas inter-relações, fazendo com que seja mais fácil admitir a perspectiva de lidar com a deficiência sem abandono ou omissão, sem estigmas, mas com realismo.

Interligado com a segurança e o afeto proporcionados pela família está também a necessidade de prover alimentos quando o deficiente não tem possibilidades de conseguir por conta própria; sobre o assunto dispõe Diniz (2009, p. 575-576):

O fundamento desta obrigação de prestar alimentos é o princípio da preservação da dignidade da pessoa humana (CF, Art. $1^{\circ}$, III) e o da solidariedade da social e familiar $\left(\mathrm{CF}, \mathrm{Art} .3^{\circ}\right)$. Trata-se de dever personalíssimo, devido pelo alimentante, em razão do alimentado. Assim, por exemplo, na obrigação alimentar um parente fornece ao outro aquilo que é necessário à sua manutenção, assegurando-lhe meios de subsistência, se ele, em virtude de idade avançada, doença, falta de trabalho ou qualquer incapacidade, estiver impossibilitado de produzir recursos materiais com próprio esforço.

Dessa forma, é dever da família, consanguínea ou decorrente do afeto, cumprir com a obrigação de alimentar a pessoa com deficiência impossibilitada de prover seu próprio sustento. Contudo, quando existem casos em que a família tem seus recursos esgotados para manter o atendimento de todas as necessidades, ou inexistência de família, abandono familiar, entre outros, a obrigação do ônus da subsistência da pessoa com deficiência passa a ser do Estado. Seja em qualquer meio social, deve permanecer sempre como ideia principal o princípio da equidade, o qual implica respeito às diferenças.

A família como pessoa mais próxima deve ajudar na promoção e garantia desse direito, de forma direta com a pessoa com deficiência, como também exigindo medidas junto à sociedade, organizando políticas eficazes na busca do bem-estar de todos.

Sobre esses assuntos dispõe a CF/88 em seu Art. 203, incisos IV e V: 
Art. 203 - A assistência social será prestada a quem dela necessitar, independentemente de contribuição à seguridade social, e tem por objetivos: IV - a habilitação e reabilitação das pessoas portadoras de deficiência e a promoção de sua integração à vida comunitária; V - a garantia de um salário mínimo de benefício mensal à pessoa portadora de deficiência e ao idoso que comprovem não possuir meios de prover à própria manutenção ou de tê-la provida por sua família, conforme dispuser a lei.

Em um primeiro momento, a chegada de um membro da família com deficiência pode se caracterizar como uma experiência extremamente penosa e desgastante, mas, com o passar do tempo, não se terá mais essa visão, desde que haja, dentro da própria família e da comunidade, medidas que ajudem na integração da pessoa com deficiência na sociedade, fazendo com que o deficiente não seja caracterizado como uma pessoa doente, mas apenas com suas diferenças.

Essa interação junto com o esclarecimento de profissionais que lidam com pessoas com deficiência faz com que exista a possibilidade de alternativas ligadas à inclusão social.

Dessa forma, fica claro que, mesmo com as dificuldades encontradas pela família, é possível encontrar soluções e fazer com que todos vivam em harmonia, através de uma sociedade que favorece a convivência humana e o respeito à diversidade.

\section{CONSIDERAÇÕES FINAIS}

A sociedade brasileira muito tem evoluído nas últimas décadas no que se refere à inclusão social da pessoas com deficiência. Tratados, convenções e leis foram inseridos no ordenamento jurídico pátrio como salvaguarda aos direitos dos deficientes, com vistas à garantia de uma vida digna e mais igualitária.

Não obstante a existência de políticas inclusivas, o fato é que, ao se olhar a fundo para a coletividade, denota-se que ainda se está distante de uma sociedade inclusiva de fato. Apesar do 
aparato regulador acerca da inclusão social em empregos, escola e saúde, por exemplo, implicitamente é marcante a presença da discriminação com os portadores de deficiência, seja ao falar, olhar, pensar ou tratar essas pessoas.

Há que se considerar que o problema pode ser mais complexo do que se imagina, como ocorre no âmbito empregatício. As pessoas com deficiência acabam sendo objeto de permuta entre empregador e governo, de modo que a contratação, em sua maioria, visa apenas ao preenchimento das cotas reservadas para essas pessoas, evitando-se multas. Uma jogada de interesses econômicos e capitalistas, pura e simplesmente.

Dessa forma, a postura que a sociedade apresenta frente às pessoas portadoras de deficiência, na maior parte dos casos, ainda é a de compaixão. Os indivíduos sociais não se desvencilharam da herança preconceituosa que muito já manchou a história brasileira na luta pela igualdade, e o "diferente", como alguns utilizam o termo, ainda é visto com receio.

Portanto o discurso social nada mais é do que a exteriorização de uma teoria não alcançada. Muito mais do que falar em inclusão social, é preciso vivê-la de fato, de modo que seja uma representação do desejo social, e não mera manifestação de opiniões. 0 processo para uma sociedade inclusiva deve ser endógeno, e não exógeno, como tem ocorrido.

Por fim, faz-se, então, necessária a internalização social do sentimento de igualdade para, posteriormente, a inclusão acontecer concretamente. As iniciativas e medidas de inclusão social devem partir da própria sociedade, como forma de alertar e mobilizar o Estado sobre a importância das pessoas com deficiência no desenvolvimento social, o qual somente será possível após a ativação da totalidade dos agentes sociais. 


\section{REFERÊNCIAS}

ARAUJO, Luiz Alberto David. A proteção constitucional das pessoas portadoras de deficiência. 4. ed. Brasília: CORDE, 2011.

BRASIL. Constituição da República Federativa do Brasil 1988. Disponível em: <http://www.planalto.gov.br/ccivil_03/_ato2007-2010/2009/ decreto/d6949.htm>. Acesso em: 24 mar. 2013.

. Decreto $n^{\circ} 7612$, de 17 de novembro de 2011. Disponível em: <http://www.brasil.gov.br/viversemlimite>. Acesso em: 24 mar. 2013.

. Lei $n^{\circ}$ 7.853, de 24 de outubro de 1989: Dispõe sobre o apoio às pessoas portadoras de deficiência, sua integração social, sobre a Coordenadoria Nacional para Integração da Pessoa Portadora de Deficiência - Corde. Disponível em: <http://www.planalto.gov.br/ ccivil_03/leis/L7853.htm>. Acesso em: 23 mar. 2013.

. Lei $n^{\circ}$ 8.080, de 19 de setembro de 1990: dispõe acerca dos parâmetros para a atuação do SUS - Sistema Único de Saúde. Disponível em <http://portal.saude.gov.br/portal/arquivos/pdf/lei8080.pdf>. Acesso em: 23 mar. 2013.

BUSCAGLIA, Leo. Os deficientes e seus pais. 3. ed. Rio de Janeiro: Record, 1997.

CANOTILHO, J. J. Gomes; MOREIRA, Vital. Constituição da República Portuguesa anotada. 4. ed. Coimbra: Coimbra Editora, 2007. v. I.

DINIZ, Maria Helena. Curso de direito civil brasileiro. São Paulo: Saraiva, 2009. v. 5.

GUGEL, Maria Aparecida. Pessoas com deficiência e o direito ao concurso público: reserva de cargos e empregos públicos, administração pública direta e indireta. Goiânia: Ed. da UCG, 2006.

Instituto Brasileiro de Geografia e Estatística (IBGE). Censo Demográfico 2010: características gerais da população, religião e pessoas com deficiência. Disponível em: <http://www.ibge.gov.br/ home/estatistica/populacao/censo2010/caracteristicas_religiao_ deficiencia/default_caracteristicas_religiao_deficiencia.shtm $>$. Acesso em: 26 mar. 2013. 
KONZEN, Afonso Armando. 0 direito à educação escolar. E-GOV - portal de e-governo, inclusão digital e sociedade do conhecimento, Porto Alegre, 1999. Disponível em: <http://www.google.com.br/url?sa=t\&r $\mathrm{ct}=\mathrm{j} \& \mathrm{q}=\&$ esrc $=\mathrm{s} \&$ source $=$ web $\& \mathrm{~cd}=8 \& \mathrm{cad}=\mathrm{rja} \&$ uact $=8 \& \mathrm{ved}=0 \mathrm{CEAQFj}$ AH\&url=http $\% 3 \mathrm{~A} \% 2 \mathrm{~F} \% 2 \mathrm{Fwww}$.egov.ufsc.br\%2Fportal\%2Fsites $\% 2 \mathrm{~F}$ default $\% 2$ Ffiles\%2Fanexos\%2F32572-39735-1-PB.pdf\&ei=F9g0U-eC FM6nsASq34CgAQ\&usg=AFQjCNEVIJWczzY030AnGxNIObalTf7tBg>. Acesso em: 24 mar. 2013.

MANTOAN, Maria Tereza. Inclusão escolar. O que é? Por que? Como fazer? 1. ed. São Paulo: Moderna, 2003.

MARMELSTEINS, George. Curso de direitos fundamentais. 3. ed. São Paulo: Editora Atlas, 2011.

ORGANIZAÇÃO DA NAÇÕES UNIDAS (ONU). Convenção Internacional sobre os direitos das pessoas com deficiência, [s.d.]. Disponível em: <http://www.planalto.gov.br/ccivil_03/_ato2007-2010/2009/decreto/ d6949.htm>. Acesso em 24 mar. 2013.

ORGANIZAÇÃO MUNDIAL DA SAÚDE (OMS). Constituição da Organização Mundial da Saúde - 1946. Biblioteca Virtual de Direitos Humanos, São Paulo, [s.d.]. Disponível em: <http://www.direitoshumanos. usp.br/index.php/OMS-Organiza\%C3\%A7\%C3\%A3o-Mundial-daSa\%C3\%BAde/constituicao-da-organizacao-mundial-da-saudeomswho.html>. Acesso em: 23 mar. 2013.

PAULO, Vicente; ALEXANDRINO, Marcelo. Direito constitucional descomplicado. 7. ed. São Paulo: Editora Método, 2011.

RIBAS, João Baptista Cintra. 0 que são pessoas deficientes. 2. ed. São Paulo: Brasiliense, 1985.

SARLET, Ingo Wolfgang. Dignidade da pessoa humana e direitos fundamentais na Constituição Federal de 1988. 2. ed. rev. e ampl. Porto Alegre: Livraria do Advogado Editora, 2002.

WERNECK, Claudia. Ninguém mais vai ser bonzinho na sociedade inclusive. 2. ed. Rio de Janeiro: WVA, 2000. 